\title{
Automatic Weed Killing Robot for Agriculture Purpose and Insect Killing
}

\author{
Tejas Badkhal ${ }^{1}$, Rohit Sharma ${ }^{2}$, Igve Sonu ${ }^{3}$, Sanket Patil ${ }^{4,}$ Dr. Rahul Mapari ${ }^{5}$ \\ E\&TC Engineering Department ${ }^{1,2,3,4,5}$ Student ${ }^{1,2,3,4}$ Assitant Professor ${ }^{5}$ \\ Email: tejas.badkhal@gmail.com ${ }^{1}$, sharmaroc11@gmail.com ${ }^{2}$, igvesoni@gmail.com ${ }^{3}$ \\ ssanketpatil721@gmail.com ${ }^{4}$, rahul.mapari@pccoer.in $^{5}$
}

\begin{abstract}
Comprehensive review of autonomous robotic weed control systems, reported that systems for plant detection and their classification (crop vs. weed) conferred the best technical challenge for development of a victorious weeding mechanism. Methods for precision weed control also needed further development. Although the few fully autonomous robotic weeding systems that had been developed at the time showed promise for reducing hand labor and/or pesticide requirements, none had been successfully commercialized. Since then, technology has advanced and a number of other machine-driven weeding machines area unit commercially offered. This paper describes some of these devices and provides an update on the current state of robotic weeding. Commercial robotic weeding machines utilize one of several means to kill weeds including mechanical, flame or herbicidal spray. Classifying plants as either crop or weeds is difficult with system accuracy of around only $70 \%$, even under ideal conditions. There are many ways to identify crop plants in digital images, but typically this is done by first analyzing a captured imaged and classifying each pixel in the image as being either a plant or a non-plant part using some type of green threshold technique. Herbicides are used worldwide to manage agricultural weeds. Over $95 \%$ of herbicides reach a destination other than their target crops, because they are sprayed or spread everywhere in the agricultural fields. This causes many unwanted effects on environment, humans and other living organisms. The automatic weed control systems provide efficient method of weed removing within the rows and inter rows. The machine vision system has been used to detect and differentiate the weeds from the crop. Guidance system has been used to track the rows with accuracy and to control a row cultivator and an autonomous agricultural robot in real-time. Mechanical methods of automatically removing weeds from the sideline two basic designs are used: a mechanical knife removes weeds from the inter rows and rotating hoe are used to remove the weeds from the within rows. The proposed system is helpful to avoid the usage of herbicides in the agriculture field and also replaces the shortage of labor.
\end{abstract}

Index Terms- Machine vision; Guidance System; Semantic segmentation; Agriculture.

\section{INTRODUCTION}

India is the seventh largest country in the world and the second biggest in Asia after China. Inspite of being a country of huge size, India is a country of Agriculture and has a wide range of soil types depending on the climatic condition of the region, it has land area of about $15,200 \mathrm{kms}$ and a coastline of 7,516kms. India measures $3214 \mathrm{~km}$ from north to south and $2933 \mathrm{~km}$ from east to west and farming being the backbone of the economy [1]. The country experiences different ranges of temperature from Arctic cold to dessert from heavy rainfall to scanty rainfall. India has farm produce which satisfy 17.6 billion population of its own primarily. Even if a lot of improvement is done in farming technology with respect to the machinery and the farming methodology or the improved variety of the seed used in actual, still there is no significant improvement in the weed killing techniques [2]-[4]. Now actually what is a weed? A weed can be generally stated as anything which grows along with crop on the field irrespective of the actual crop is known as weed. In the developing countries or countries like India which is a price sensitive market, traditional method is more preferred as the machinery are expensive and the availability of skilled operator is difficult at times. Weed is still one of the most prominent problem on the field if farming is concerned, a study suggests initially there is no harm to the actual crop from weed during the time span of 3-4 weeks after sowing but after that race for the survival starts as need for more space, more nutrients, more sunlight and more water is felt. [5]-[7] Weed initially decreases the growth speed of the actual plant due to sharing of the resources, according to a study it was found that the yield of crop with presence of weed into the field was around $30-80 \%$ lower per hectare compared field with no weed.

As the report suggest India witnessed a total grain production of $277.49 \mathrm{mn}$ tonnes in the fiscal year 2017-2018 and $31.5 \%$ was lost or the yield was reduced due to presence of weed in the farm.

That means the actual production would have been if weed were not there $=402.15 \mathrm{mn}$ tonnes If this $31.5 \%$ would have been converted into a successful yield then an additional 2.63 billion population could have been served with food. 


\section{E-ISSN: 2321-9637 \\ Available online at www.ijrat.org}

Hence, a successful weed management system is required to increase the yield of the crops lost due to weed presence. The system should be smartenough to classify between the weed and actual crop, it should be an automated system so as to reduce the labour work on the farm, such a system would be known as Automatic Weed Killing Robot [9]. This system will reduce the human activity on the farm, it will increase the speed of work as machines can work under any conditions from extreme rainy season, to extreme cold and extreme hot seasons. The system will consists of a processing board, it will be responsible for all the processing and the image enhancing work to be carried on the plant, the captured will be compared with the test image already present in the system and the action will be taken depending on the decision passed by the processor.

\section{LITERATURE REVIEW}

Controlling the weeds within the agriculture field may be a huge deal in agriculture crop production. Maximum ninetieth of weeds are controlled by victimization herbicides (chemical weed killer). Reducing weed killer choices, concern of well water contamination, and client pressure to ignore weed killer use, ar all pushing the farmers to removed from reliance on herbicides. Hand weeding is also not effective and not suitable for large range. To overcome these problems in weeding, automatic detection and weed control system detects the weed in the field and remove it mechanically. This system uses two machine vision systems: one to guide the agriculture robot along the field and another is to identify the crops and weeds by its color and shape parameters. Weeds removal is achieved with mechanical hoe. Weeds within the repose row and at intervals row conjointly removed by this hoe and rotating disc. This system is highly useful to reduce the usage of herbicide and the shortage of labors.

Weed removal can be applied for the following purpose:

a) Identifying the crop and weeds in fields.

b) Classifying the weed among crops.

c) Mechanical weed removal in respective areas.

The automatic weed removal system uses two mechanical hoes (knives and circular disc) for the removal of weeds in fields.

\section{PROPOSED METHODOLOGY AND OBJECTIVES}

\subsection{Proposed methodology}

- Open-CV (Open supply laptop Vision) is library of programming operate principally geared toward period laptop vision.
- Originally developed by Intel, it was later supported by Willow Garage (which was later acquired by Intel).

- The library is cross-platform and free to be used beneath the ASCII text file BSD license.

- Open-CV was engineered to produce a typical infrastructure for laptop vision applications and to accelerate the utilization of machine perception within the industrial merchandise.

- These algorithms can be used to detect and recognize faces, identify objects, classify human actions in videos, track camera movements, remove red eyes from images taken using flash etc.

- Raspberry pi will be the computing hardware of the system, it will be responsible for computing the necessary enhancement in the image will would be captured by a camera mounted on the robot.

- The system will perform the necessary actions based on the decisions given from the system after comparing with the test image preloaded into system.

- The pneumatics system will be responsible for controlling the spraying movement of the chemicals stored in the storage tank.

- The To-and-Fro movement of the robot will be controlled by the Arduino board based on the inputs received from the Raspberry $\mathrm{Pi}$.

\subsection{Objectives}

- $\quad$ To capture the image of the plants and classify between weed and crop.

- $\quad$ To improve the overall reliability of the system.

- $\quad$ To reduce the maintenance cost.

- To improve the speed of the work on the farm.

- $\quad$ To provide an all-weather system for operation.

- To increase the farm yield.

- To reduce the use of fertilizers and chemicals as much as possible. 


\section{Available online at www.ijrat.org}

\section{FLOWCHART}

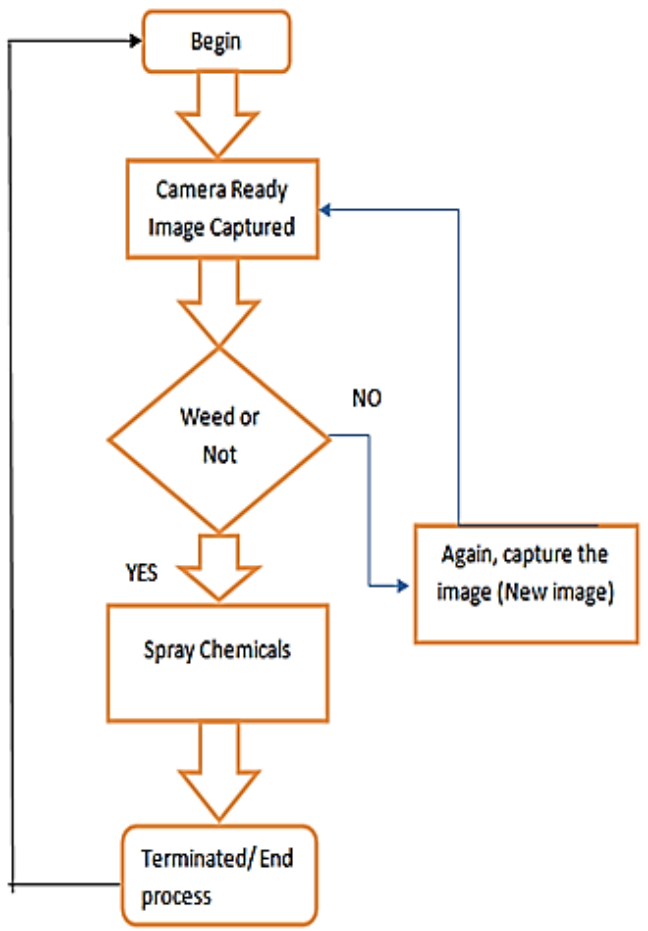

Fig.1. This the flow chart for functioning of the system.

- As the flowchart suggests the robot will start it's operation as soon as the start button is pressed.

- The camera will start capturing the image and will analyze the with the test image if any present.

- If weed is present then spraying action of chemical will be done.

- If weed is nor present the robot will move on and futher images will be captured.

\section{CIRCUIT DIAGRAM}

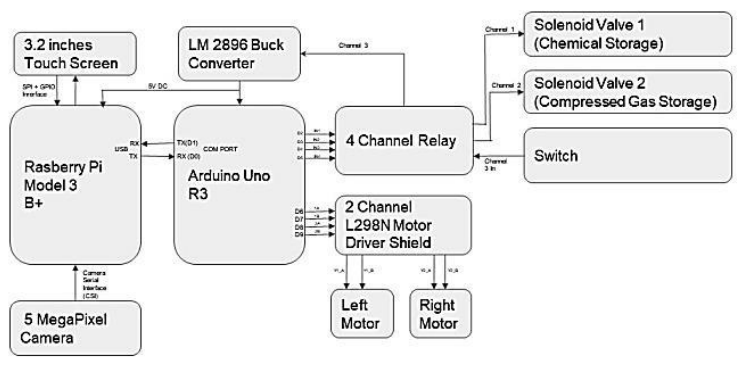

Fig. 2. This is the circuit connection diagram for the system.

- The 3.2 inches color LCD connects to the Rasberry Pi 3 B+ with SPI Interface for the graphics and touch information. It has 3
Buttons which can be allotted to any function as per user requirement.

- These buttons connect Rasberry Pi 3 B+ with GPIO pins. The camera interface is with dedicatedly provided Camera Serial Interface (CSI).

- The Arduino will connect to the Rasberry Pi $3 \mathrm{~B}+$ with Serial Port.

- The Serial Port at the Rasberry Pi $3 \mathrm{~B}+$ is software based USB Serial Port. At the Arduino side, the Serial Port is hardware serial port (D0 \& D1).

- $\quad 3$ Relays will be used. Relay 1 takes input from Arduino at pin D2. Relay 2 takes input from D3.

- $\quad$ Relay 3 input will be connected to the switch which controls +5VDC power rail to the Rasberry Pi $3 \mathrm{~B}+$ and Arduino.

- Two motors connect to the provided output terminals (Y1_A, Y1_B \& Y2_A, Y2_B). Input for motor driver shield connects to the $1 \mathrm{~A}, 1 \mathrm{~B} \& 2 \mathrm{~A}, 2 \mathrm{~B}$ on the shield side and on the Arduino side it connects to D6, D7, D8, D9. Relay 1 output channel connects to solenoid 1, Relay 2 output channel connects to solenoid 2 .

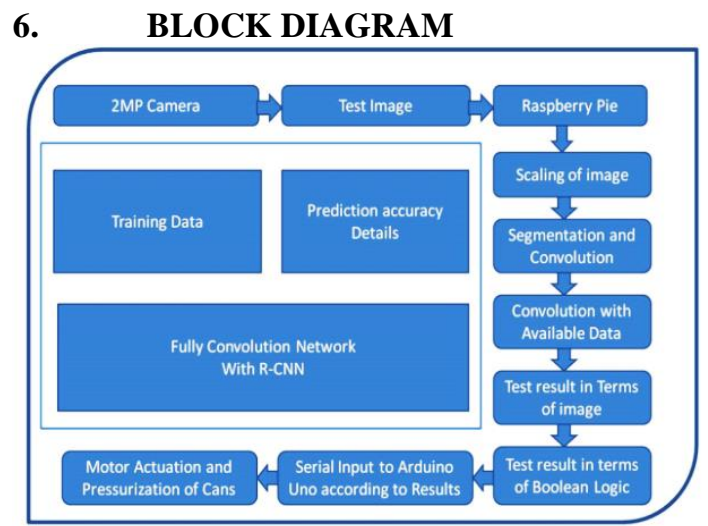

Fig.3. This is the block diagram for overall system

\section{- CAMERA}

Whenever the robot will be powered on, the Camera which is of 5MP will start capturing the images of the plants in field.

\section{- $\quad$ Test Image}

A reference image will already be stored in the memory unit of the Weed killer, this will in identifying the type of weed if, there is any weed present in the robot.

- Raspberry Pi

The raspberry pi unit is the heart of the weed killer, all the processing and decision related to robot will be taken by the raspberry pi unit. The processing will include many steps such as segmentation of the 


\section{E-ISSN: 2321-9637 \\ Available online at www.ijrat.org}

captured image, comparing the captured image with the image of a plant with weed and different convolution and windowing techniques to enhance the quality of the image.

- Arduino Uno

The Arduino is the second processor used in the weed killer which is an open source platform based processor. The Arduino will deal with the actions to be performed upon the inputs provided to it via raspberry pi. The actions which may be performed are spraying of the chemicals or the movement of the robot to the next crop if weed is no detected in the corresponding crop.

\section{ACKNOWLEDGMENTS}

I would like to express my special thanks of gratitude to my guide (DR. R.G Mapari) who gave us the golden opportunity to do this wonderful project on the topic (Automatic Weed Killing Robot), We came to know about so many new things I am really thankful tothem.

Secondly, I would also like to thank my parents and friends who helped me a lot in finalizing this project within the limited time frame.

\section{CONCLUSION}

We will be learning to solve an integrated approach of different Engineering discipline such mechanical, electronics and control engineering to build a useful product which can solve the problem of farmers. With the help of the project there will be high possibility of restricting the use of chemicals in the farm and resolve other harmful effect such as loss of fertility of land due to excess chemicals and contamination of ground water. The technology will be much more human friendly and the electronics can be used for betterment of farmers to increase the productivity. The farmers will be better at handling farming activities and will be able to focus more on the management and increasing the yield. There will be faster development phase. The Farmers will be able to reduce chemical use resulting in reduced expenditure and higher profits. Also lesser use of chemicals increase soil quality and prevent ground water contamination. Not only farmers will be able to use and increase their productivity but even government organizations and public and private sector industries will be able to control weeds and pests in their premises. The overall benefits this system holds is countless. Further a more accurate and precise machineries can be viewed in next few years which will advanced by the industrial experts and engineering students. This system includes use of knowledge of mechanical, electronics and computer science. By inclusion of knowledge from each stream with scientific knowledge, the system has a larger space for the development.

\section{REFERENCES}

[1] Fennimore, S.A., R.F. Smith, L. Tourte, M. LeStrange and J.S. Rachuy. 2013. Evaluation and Economics of a Rotating Cultivator in Bok Choy, Celery, Lettuce, and Radicchio Weed Technology. In-Press.

[2] Siemens, M.C., R. Herbon, R.R. Gayler, K.D. Nolte and D. Brooks. 2012. Automated Machine for thinning lettuce - Evaluation and development. ASABE paper No. 12-1338169, pp. 14. St. Joseph, Mich: ASABE.

[3] Slaughter, D.C., Giles, D.K. and D. Downey. 2008. Autonomous robotic weed control Systems: A review. Computers and Electronics in Agriculture 61: 63-78.

[4] Chirsty L Sprague. 2017 Weed Control Guide For Field Crops. Michigan State university.

[5] Rahul Ganpat Mapari, Dr. D. G. Wakde, R. G. Tambe, A. B. Kanase, Shivajirao Patil, "Modeling and Simulation of the Single-Phase Unity Power Factor Active Rectifier for Minimizing the Input Current Harmonic Distortions", Int. Journal of Applied Mechanics \& Material., vol. 267, pp. 9194, (2013).

[6] Rahul Ganpat Mapari, Dr. D. G. Wakde, "Modeling, Simulation and Implementation of the Single-Phase Unity Power Factor Active Rectifier for Minimizing the Input Current Harmonic Distortions", Proceedings of IEEE/ICCPCT, pp. 265-268, (2013).

[7] Rahul S. Parbat, Sagar D. Mahamine, Shekhar H. Bodake, Mahesh P. Aher, "Dual Polarized Triple Band Microstrip Antenna for GSM/WiMAX/WLAN Applications”, 2016 International Conference on Automatic Control and Dynamic Optimization Techniques (ICACDOT), IEEE, 2016.

[8] RS Parbat, AR Tambe, MB Kadu, RP Labade, "Dual polarized triple band $4 \times 4$ MIMO antenna with novel mutual coupling reduction approach", 2015 IEEE Bombay Section Symposium (IBSS), 2015.

[9] RS Parbat, MB Kadu, RP Labade, "Design of immensely isolated $2 \times 2$ MIMO antenna for dualpolarized triple-frequency applications", 2015 IEEE Bombay Section Symposium (IBSS), 2015. 